\title{
The Five Major Divisions (“Kingdoms") of Life
}

\author{
Gregory Eldredge
}

Published online: 20 November 2007

(C) Springer Science + Business Media, LLC 2007

The following lesson plan was originally used in a ninth grade special education biology class. Students require some background knowledge on the characteristics of the five major divisions of life ("kingdoms"). For the purposes of this lesson, prokaryotes ("bacteria") are recombined into one major group, the Monerans. To adapt this lesson for a more advanced group, find additional reproducible illustrations that clearly show the differences between Archaea and Bacteria.

Aim: How can we classify organisms?

Instructional Objectives (students will be able to...)

-Explain how and why living things are divided into kingdoms.

-List and describe the five kingdoms of living things.

-Work cooperatively with peers.

National Science Education Content Standards:

- Unifying Concepts and Processes in Science

-Systems, order, and organization

-Evidence, models, and explanation

-Form and function

Materials: Biota images handouts, poster board, scissors, glue, markers, class notes.

Lesson:

1. Introduction: (Written on board)

-Imagine you discovered a new organism. How would you figure out which kingdom it belongs to?

Illustrations by Mike Gaspar.

G. Eldredge $(\bowtie)$

Mercer County Court House,

P. O. Box 8068, Room 203209 South Broad \& Market Streets,

Trenton, NJ 08650-0068, USA

e-mail: Gregory.Eldridge@Judiciary.State.NJ.US
2. Discuss student responses:

Guiding Questions:

-If the organism consists of only one cell, which kingdom could it fit into? Why? (Protist or moneran)

-If the organism had many cells, which kingdom could it fit into? Why? (Plant, animal, fungi)

-Which kingdom could it be if the organism makes its own food? Why? (Plant or Protist)

-How could we tell if the organism was an animal?

3. Hands-on activity:

Students will be organized in groups of three or four. In groups, students will use poster board to draw a large table with five columns representing the five kingdoms of lifeMonerans, Protists, Fungi, Plants, and Animals (this chart will be modeled on the board for students to follow.) Students will then take the handouts, cut out the images of different organisms, and arrange them by taxonomic kingdom using their notes from previous lessons and intergroup discussion.

4. Closing discussion:

Students prepare a brief written response to the following question to share with the class:

-If every organism on Earth fits into one of the five kingdoms, where does the human species fit in? Why?

Students then discuss their response during the final moments of class.

5. Homework:

In three to four complete sentences, answer the following question:

-What would happen if someone told you that humans were not animals? How would you explain to them that we actually are? 


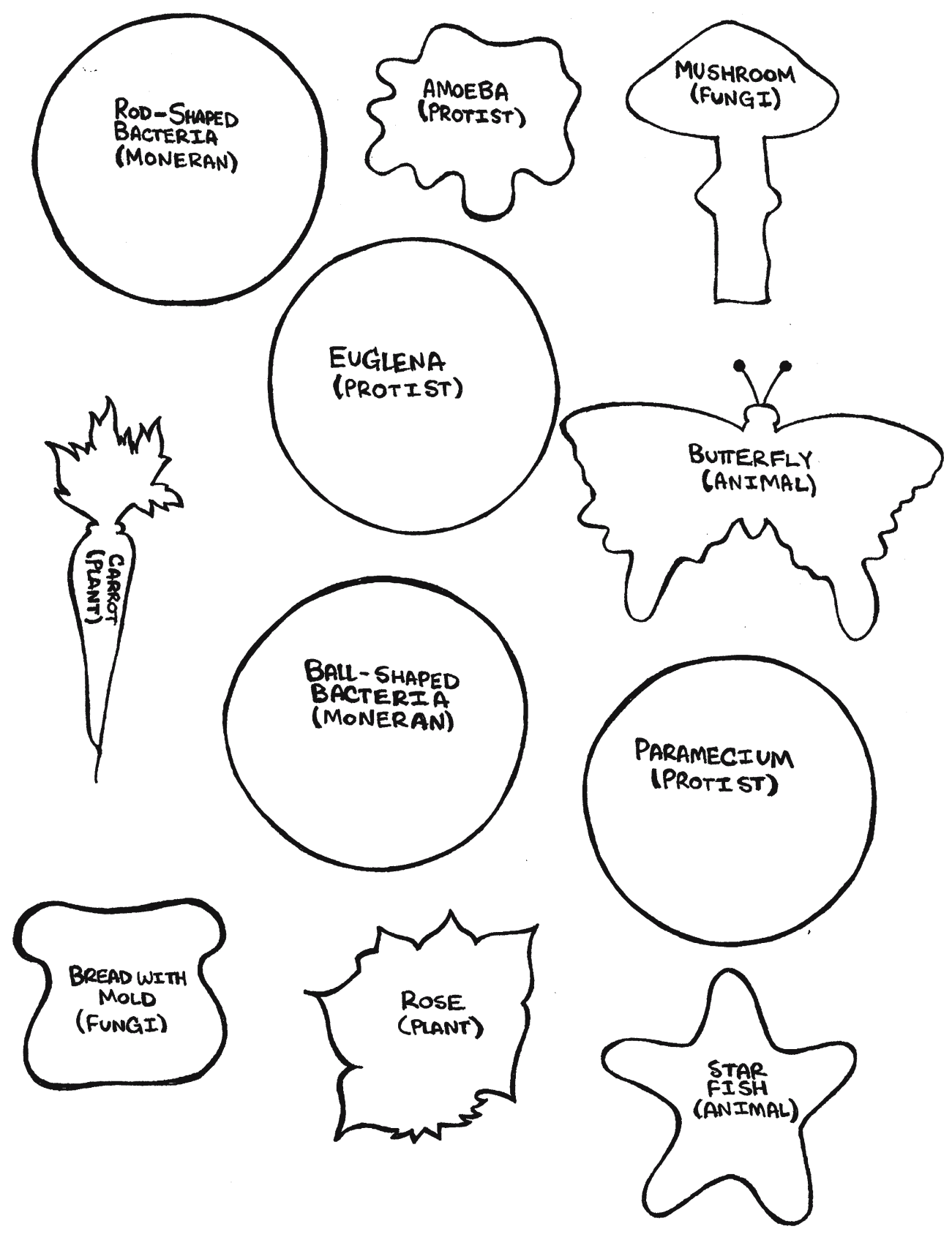




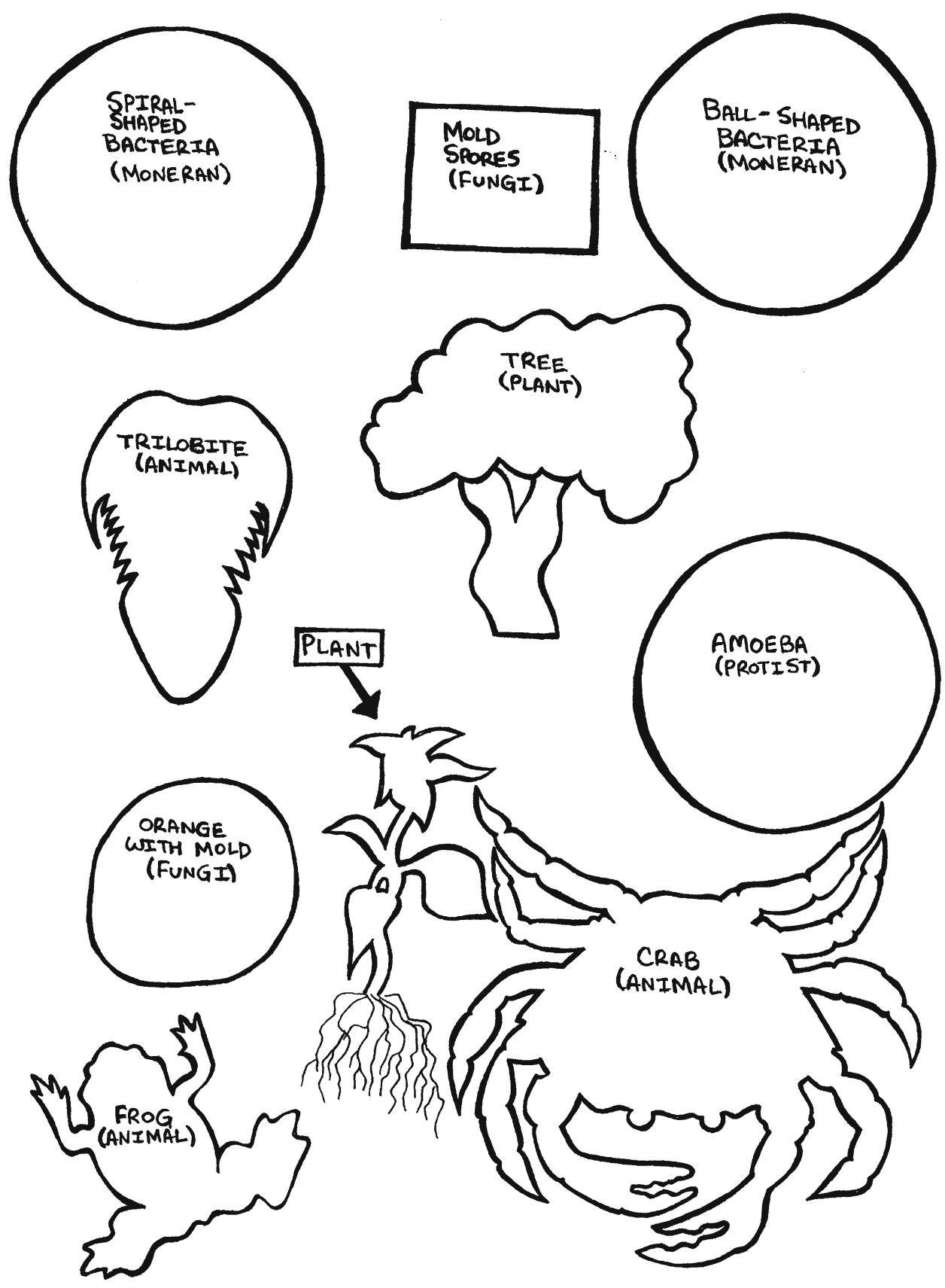

